\title{
Examining the Impact of Bias Correction on the Prediction Skill of Regional Climate Projections
}

\author{
Isaac Mugume1, Triphonia Ngailo², Ronald Semyalo ${ }^{3}$ \\ ${ }^{1}$ Department of Geography, Geo-Informatics \& Climatic Sciences, Makerere University, Kampala, Uganda \\ ${ }^{2}$ Department of General Studies, Dar es Salaam Institute of Technology, Dar es Salaam, Tanzania \\ ${ }^{3}$ Department of Zoology, Entormology and Fisheries Sciences, Makerere University, Kampala, Uganda \\ Email: imugume@caes.mak.ac.ug, ronald.semyalo@gmail.com, triphongailo@gmail.com
}

How to cite this paper: Mugume, I., Ngailo, T. and Semyalo, R. (2020) Examining the Impact of Bias Correction on the Prediction Skill of Regional Climate Projections. Atmospheric and Climate Sciences, 10, 573-596.

https://doi.org/10.4236/acs.2020.104030

Received: January 2, 2020

Accepted: October 17, 2020

Published: October 20, 2020

Copyright $\odot 2020$ by author(s) and Scientific Research Publishing Inc. This work is licensed under the Creative Commons Attribution International License (CC BY 4.0).

http://creativecommons.org/licenses/by/4.0/

\begin{abstract}
Rainfall is crucial for many applications e.g. agriculture, health, water resources, energy among many others. However, quantitative rainfall estimation is normally a challenge especially in areas with sparse rain gauge network. This has introduced uncertainties in rainfall projections by climate models. This study evaluates the performance of three representative concentration pathways, RCP i.e. 4.5, 6.0 and 8.5 over Uganda using the Weather Research and Forecasting (WRF) model. It evaluates the model output using observed daily rain gauge data over the period 2006-2018 using Pearson correlation; relative root mean square error; relative mean error and skill scores (accuracy). It also evaluates the potential improvement in the performance of the WRF model with respective RCPs by applying bias correction. The bias correction is carried out using the quantile mapping method. A poor correlation with observed rainfall is generally found $(-0.4$ to +0.4$)$; error magnitudes in the ranges of 1 to 3.5 times the long-term mean are observed. The RCPs presented different performances over different areas suggesting that no one RCP is universally valid. Application of bias correction did not produce realistic improvement in performance. Largely, the RCPs underestimated rainfall over the study area suggesting that the projected rainfall cases under these RCPs could be seriously underestimated. However, the study found RCP8.5 with slightly better performance and is thus recommended. Due to the general weak performance of the RCPs, the study recommends re-evaluating the assumptions under the RCPs for different regions or attempt to improve them using data assimilation.
\end{abstract}

\section{Keywords}

Representative Concentration Pathways, WRF Model, Rainfall Projections 


\section{Introduction}

Developing countries e.g. Uganda normally suffer from the adverse impacts of extreme climate. Studies on future climates e.g. Tiyo et al. [1], Okonya et al. [2], Ongoma et al. [3], among others have generally projected increasing magnitudes and frequency of extreme weather events. Unfortunately, developing countries have lower adaptive capabilities [4] [5] [6] and less developed early warning mechanism [3] [6] which make them vulnerable to the negative impacts associated with these extreme events. The changes in climate have been attributed to increasing pollution levels and changes in environment due to changes in land cover and land use. Consequently, the concentration of atmospheric pollutants has been conceptualized into Representative Concentration Pathways (RCP) [7]. Four RCPs have been proposed, namely RCP2.6, RCP4.5, RCP6.0 and RCP8.5 [3] [7].

Future climate studies using General Circulation Models (GCMs) e.g. Giannini et al. [8], Kisembe et al. [9] among others, have projected enhanced wet conditions over East Africa. This is due to the weakening of moisture convergence over the Congo basin [8] [10]. The GCMs are normally used for simulating the climate on different spatial scales, i.e. mesoscale, regional and global scale [9] including different time-scales i.e. days, weeks, months, years and decades. However, these GCMs have been found to have coarser horizontal resolutions which are not useful for regional high impact studies [5] [9] [11]. An evaluation of selected 10 models within CODEX by Kisembe et al. [9] revealed that most regional climate models (RCM) reproduce the inter-annual rainfall variability but present a poor skill in reproducing the rainy seasons especially the March-May rainfall season. Additionally, dry days are normally overestimated and presented as drizzles in these numerical models [10] [12] [13].

An approach normally proposed to address the limitations of the GCM is using bias correction. It has been used in many studies e.g. Sharma et al. [14], Ghimire et al. [15], Noor et al. [7], Cannon et al. [16], Monaghan et al. [17], Piani et al. [13] among others. By carrying out statistical bias correction on daily rainfall, Piani et al. [13] found an improvement in the mean and representation of extreme events like droughts. Ghimire et al. [15] argue that bias correction results in reduced biases and improves accuracy of simulations. For this reason, Noor et al. [7] evaluated the bias correction methods i.e. linear scaling, gamma quantile mapping, generalized quantile mapping, and power transformation and noted that the power transformation method was the most suitable for bias correction of the GCM. However, Myo et al. [18] and Ghimire et al. [15] found the linear scaling method to produce the best performance and recommended it for hydrological studies at river basins. On the other hand, Mahmood \& $\mathrm{Mu}$ kand [19], and Sharma \& Kumar [14] recommended the quantile mapping bias correction method. This could suggest that no one method is universally valid.

Additional efforts to improve the projections of GCMs using dynamical 
downscaling of RCMs have been proposed. This method has also been used in many studies e.g. Ouédraogo et al. [5], Kisembe et al. [9], Nalukwago et al. [20], among others. The RCMs are useful in down-scaling the coarse resolution of the GCMs to a higher resolution which is potentially useful for high impact studies [9] [21]. This is because the RCMs have a better representation of local features e.g. mountains [5] [9], land-cover and water bodies than the GCM [9] [21]. However, these RCMs normally inherit biases from the parent GCM [5] [21] which predisposes them to require robust validation over areas of interest before they can be reliably used.

It is therefore necessary to have a realistic representation of climate fields especially rainfall in climate models for high impact studies [11]. This is because understanding the physical basis of the climate models will help us to advance better prediction as argued by Giannini et al. [8]. Equally important is to have deeper understanding of the biases of these climate models at different spatial and temporal scales. For this reason, Piani et al. [13] has recommended this to enable high impact studies for improved vulnerability assessment. Additionally, the changing frequency of extreme weather events requires a detailed assessment to build realistic future occurrences [4] [5] [22].

In order to enhance our understanding of the future climatic evaluations, a couple of studies using RCPs/GCMs and experiments e.g. CORDEX have been proposed and widely carried out. For example, Ongoma et al. [3] evaluated 22 GCMs under the Coupled Model Inter-comparison Project Phase Five (CMIP5) over East African considering RCP8.5. They used gridded satellite rainfall data-sets from the Global Precipitation Climatology Center. However, this study uses observed rainfall data-sets and contends that the RCPs are not universally valid. This is what motivated the study and it seeks to answer the question: which RCP is realistic for Uganda and how can the uncertainty be decreased for future projections.

\section{Materials and Methods}

\subsection{Data}

This study used Lateral Boundary Conditions (LBCs) from the National Center for Atmospheric Research (NCAR) [17] [23]. It validated the model outputs using monthly rain-gauge data-sets from the Uganda National Meteorological Authority for the period 2006-2018. Like many climatic data-sets in developing countries, missing data were found and these were removed from the analyses. The LBCs used were obtained from the global bias-corrected climate model output data of version 1 of NCAR's Community Earth System Model (CESM1) that participated in CMIP5 [17] [24]. These data-sets are interpolated to 26 pressure levels and are provided at six hourly intervals and at $1^{\circ} \times 1^{\circ}$ horizontal resolution [23] [24]. The variables have been bias-corrected using the European Centre for Medium-Range Weather Forecasts Interim Reanalysis for fields from 1981 to 2005 [17]. The repository (https://rda.ucar.edu/datasets/ds316.1/) pro- 
vides three input files, namely the Representative Concentration Pathway (RCP) future scenarios i.e. RCP4.5, RCP6.0 and RCP8.5. The study used these RCPs for the period 2006-2018.

\subsection{Study Area}

This study was carried out over Uganda and used 28 study locations as presented using Figure 1. Uganda is located within the latitudes: $1^{\circ} 29^{\prime} \mathrm{S}$ to $4^{\circ} 12^{\prime} \mathrm{N}$ and the longitudes: $29^{\circ} 34^{\prime} \mathrm{E}$ to $35^{\circ} 29^{\prime} \mathrm{E}$ [9] [10]. It is a landlocked country found in the eastern part of equatorial Africa [10] [12]. The country is relatively flat in the central with a few highland areas; and having mountains in the East (Mt. Elgon; Mt. Moroto) and west (Mt. Rwenzori). The country is endowed with fresh water bodies, namely Lake Victoria, Albert, Kyoga, Edward, Wamala, George among others and has a good climate condusive for agriculture [4] [20] [25]. Most areas of the country receive a bimodal rainfall distribution i.e. March-May and September-November with exception of the northern region whose rainfall distribution tend to be unimodal peaking around August [9] [12] [20].

\subsection{Study Design}

This study contends that the study carried out by Ongoma et al. [3] used GCM in the CMIP5 which were coarse i.e. largely coarse greater than $1.5^{\circ}$ about 150 $\mathrm{Km} \times 150 \mathrm{Km}$ horizontal resolution compared to the horizontal resolution used in this study i.e. $30 \mathrm{~km}$ (about $0.3^{\circ}$ ). Therefore, this study designs and runs a comparatively higher resolution validation experiment of the RCPs over Uganda and uses 28 study locations as presented in Figure 1. Additionally, the study carried out by Fotso-Nguemo et al. [27] over a comparatively similar region used gridded data-sets but this study uses observed station rainfall data-sets and uses comparatively a longer validation period i.e. 13 years (2006-2018).

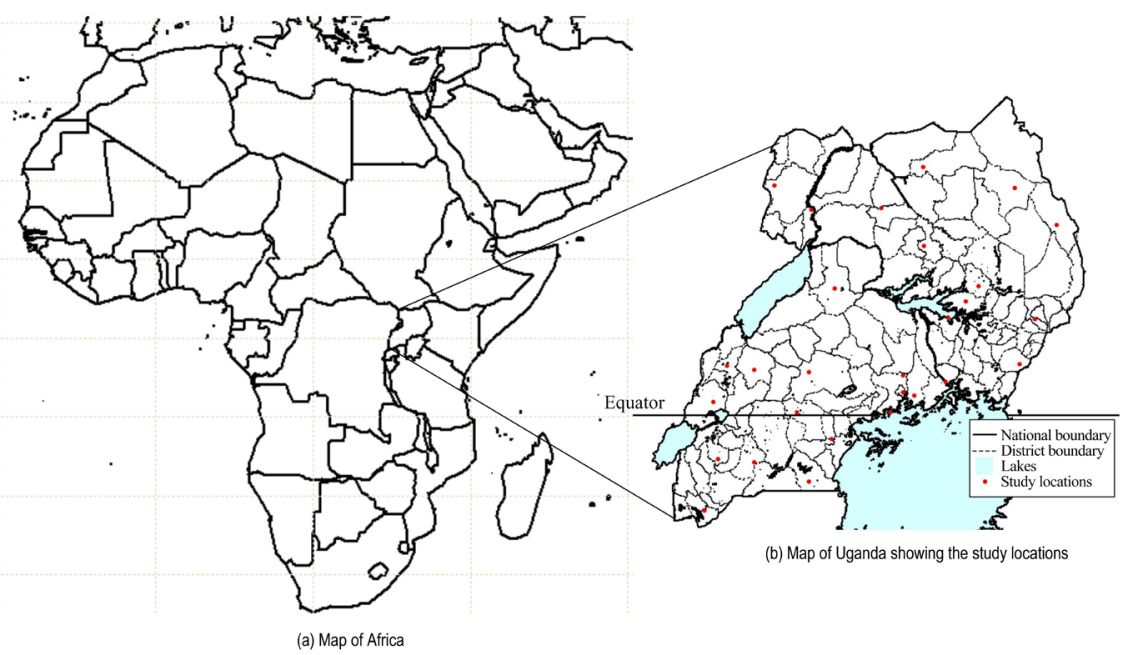

Figure 1. Shows the study area. (a) is the map of Africa showing the location of Uganda. (b) is the map of Uganda showing the study area and study locations. This figure is generated using an R-statistical programming language and the package is provided by [26]. 
This study first evaluates the performance of the RCPs in reproducing the observed climate patterns over the period 2006-2018 i.e. direct model output by running the Weather Research and Forecasting (WRF) model version 3.9 [10] [28] with boundary conditions of the three RCPs i.e. RCP4.5, RCP6.0 and RCP8.5 [17]. The direct model outputs are then bias corrected using quantile mapping (Equation (6)) to investigate any possible improvement in the performance as recommended by Sharma et al. [14], Ghimire et al. [15], Noor et al. [7], Cannon et al. [16], Monaghan et al. [17], Piani et al. [13] among others.

In running the WRF model, model the parameterization schemes used are adopted from Mugume et al. [29] and are presented using Table 1. These parameterization schemes are also used in Ingula et al. [30]. The study domain used in this study is shown using Figure 2. This study used single domain at $30 \mathrm{Km} \times$ $30 \mathrm{Km}$ covering the equatorial Africa but analyses are carried out over Uganda shown with a red box in Figure 2.

\subsection{Study Methods}

The evaluation of the WRF model performance based on the three RCPs (RCP4.5, RCP6.0 \& RCP8.5) is done using both continuous scores and categorical scores. The continuous scores comprise of the Pearson correlation coefficient, $r$, (Equation (1)) for assessing the relationship between observed and simulated; the relative root mean square error, RMSE (Equation (2)) and relative mean error, $M E$ (Equation (3)) for examining the error magnitudes. The categorical skill scores, namely the accuracy (Equation (4)) are obtained from the contingency table (Table 2).

$$
\begin{gathered}
r=\frac{\sum_{i=1}^{n}\left(p_{i}-\bar{p}\right)\left(O_{i}-\bar{O}\right)}{\left[\left(\sum_{i=1}^{n}\left(p_{i}-\bar{p}\right)^{2}\right)\left(\sum_{i=1}^{n}\left(O_{i}-\bar{O}\right)^{2}\right)\right]^{0.5}} \\
R M S E=\sqrt{\frac{1}{n} \sum_{i=n}^{n}\left[\frac{p_{i}-O_{i}}{L T M}\right]^{2}} \\
M E=\frac{1}{n} \sum_{i=n}^{n}\left[\frac{p_{i}-O_{i}}{L T M}\right]
\end{gathered}
$$

where: $p_{i}, O_{i}$, LTM, and $n$ are the model predicted $i^{\text {th }}$ value, observed $i^{\text {th }}$, long-term mean, and number of observations respectively. The relative root mean square error RMSE (Equation (2)) and the relative mean error, $M E$ (Equation 3) presented in this study are as percentage of the $L T M$ which is also used and recommended by Ongoma et al. [3]. This study used relative root mean square error and relative mean error in order to compare the performance against long-term mean.

Additionally, in this paper, the accuracy (i.e. hit rate) is defined as the proportion of hits (i.e. $A_{11}, A_{22}$ and $A_{33}$ ) (Table 2) to total observations. So in this paper for a given location, $i$, the accuracy is: 


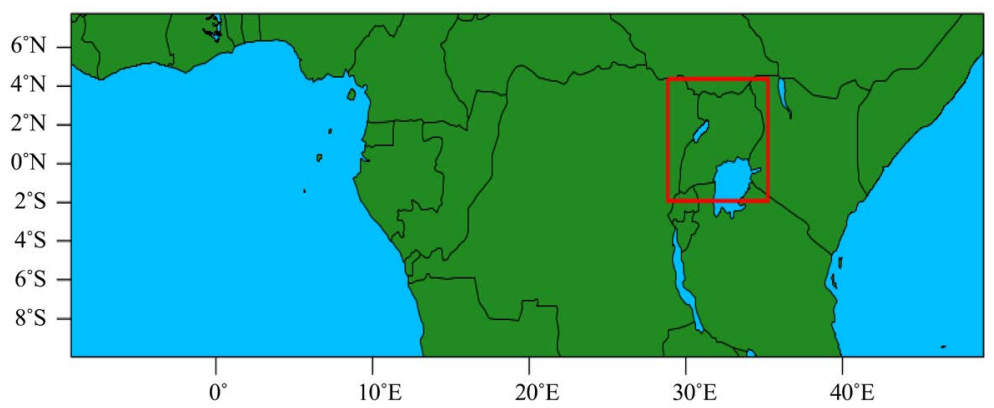

Figure 2. Shows the domain used in the study. While the domain covered the entire equatorial region, the main study was over Uganda, the red box inside the domain. The figure is generated by run an NCL programming code syntax.

Table 1. Shows the experiment set-up and the parameterization schemes in the study.

\begin{tabular}{|c|c|}
\hline Set-up/Scheme & Description \\
\hline Grid & $\begin{array}{l}\text { Staggered Arakawa C grid with } 33 \text { vertical levels and model top at } \\
100 \mathrm{hPa}[10][31]\end{array}$ \\
\hline Vertical coordinate & $\begin{array}{l}\text { Terrain-following vertical coordinate with flexible vertical grid } \\
\text { spacing [29] [32] }\end{array}$ \\
\hline Integration & Runge-Kutta $2^{\text {nd }}$ order integration option [10] [12] [33] \\
\hline Cumulus scheme & Kain-Fritsch [31] [33] \\
\hline Microphysics & WRF single moment- 6 class scheme. Recommended by [10] [34] \\
\hline Longwave & Rapid radiative transfer scheme [32] \\
\hline Shortwave & Dudhia shortwave radiation [35] \\
\hline Land surface model & Noah Land-Surface Model [36] \\
\hline Planetary boundary layer & Yonsei University planetary boundary layer scheme [10] [37] \\
\hline
\end{tabular}

Table 2. Shows the contingency table as used in the study. "Below normal" is total rainfall less than $75 \%$ of the long-term mean; "Normal" is total rainfall within $75 \%$ to $125 \%$ of long-term mean; and "Above normal" is total rainfall greater than $125 \%$ of long-term mean.

\begin{tabular}{ccccc}
\hline & & \multicolumn{3}{c}{ Model prediction } \\
\cline { 3 - 5 } & & Below Normal & Normal & Above Normal \\
\hline \multirow{3}{*}{ Observed } & Below Normal & $A_{11}$ & $A_{12}$ & $A_{13}$ \\
& Normal & $A_{21}$ & $A_{22}$ & $A_{23}$ \\
& Above Normal & $A_{31}$ & $A_{32}$ & $A_{33}$ \\
\hline \multirow{2}{c}{$A C C_{i}=\frac{A_{11}+A_{22}+A_{33}}{n}$} & &
\end{tabular}

a hit is defined in this paper as, for example when model prediction is "below normal" and the observed is also "below normal" i.e. $A_{11}$; model prediction is "normal" and observation is "normal" i.e. $A_{22}$; and model prediction is "above normal" and observation is "above normal" i.e. $A_{33}$ as illustrated in Table 2.

The contingency table used, as presented using Table 2 is based on three cases, namely "below normal", "normal" and "above normal". These terms are in operational use by UNMA and are defined as captioned in Table 2. The 
long-term mean monthly rainfall used in the study is presented using Table 3. This study also used graphical analysis of line graphs and maps obtained using inverse distance weighting interpolation [38] and given by Equation (5).

$$
p_{i}^{*}=\frac{\sum_{i=1}^{n} p_{i} w_{i}}{\sum_{i=1}^{n} w_{i}}
$$

$p_{i}^{*}$ is the interpolated precipitation amount from $p_{i}$ neighboring stations weighted with $w_{i}$ and $n$ is the total of stations used to derive $p^{*}$.

\subsection{Bias Correction Methods}

A couple of methods for bias correction have been proposed which include:

Table 3. Shows the long-term mean monthly rainfall amount in millimeters ( $\mathrm{mm}$ ) used in the study. It is derived from the different publications e.g. dekadal reports issued by UNMA.

\begin{tabular}{|c|c|c|c|c|c|c|c|c|c|c|c|c|}
\hline & Jan & Feb & Mar & Apr & May & Jun & Jul & Aug & Sep & Oct & Nov & Dec \\
\hline Arua & 18 & 37 & 91 & 120 & 128 & 146 & 155 & 217 & 173 & 210 & 125 & 30 \\
\hline Buginyanya & 45 & 73 & 124 & 217 & 234 & 180 & 190 & 243 & 199 & 217 & 134 & 41 \\
\hline Bushenyi & 75 & 110 & 110 & 157 & 80 & 46 & 42 & 81 & 120 & 141 & 143 & 121 \\
\hline Entebbe & 90 & 96 & 177 & 274 & 258 & 102 & 67 & 83 & 80 & 111 & 162 & 119 \\
\hline Gulu & 17 & 29 & 85 & 166 & 176 & 152 & 169 & 238 & 175 & 187 & 109 & 37 \\
\hline Jinja & 66 & 54 & 118 & 191 & 136 & 78 & 65 & 112 & 111 & 159 & 177 & 94 \\
\hline Kabale & 65 & 81 & 113 & 140 & 98 & 29 & 20 & 54 & 99 & 111 & 117 & 89 \\
\hline Kakoge & 36 & 41 & 111 & 161 & 137 & 59 & 76 & 101 & 133 & 164 & 128 & 55 \\
\hline Kamenyamigo & 52 & 46 & 116 & 145 & 104 & 39 & 21 & 51 & 87 & 116 & 113 & 76 \\
\hline Kasese & 31 & 40 & 116 & 152 & 106 & 54 & 31 & 84 & 64 & 123 & 101 & 68 \\
\hline Kibanda & 52 & 47 & 70 & 137 & 121 & 41 & 19 & 36 & 60 & 82 & 85 & 73 \\
\hline Kitgum & 25 & 23 & 77 & 138 & 148 & 148 & 136 & 154 & 142 & 166 & 81 & 36 \\
\hline Kituza & 93 & 65 & 142 & 188 & 127 & 70 & 71 & 116 & 142 & 169 & 188 & 144 \\
\hline Kotido & 6 & 33 & 83 & 100 & 105 & 131 & 118 & 84 & 58 & 90 & 7 & 7 \\
\hline Kyembogo & 13 & 40 & 172 & 167 & 86 & 79 & 63 & 81 & 130 & 204 & 225 & 99 \\
\hline Kyenjojo & 25 & 49 & 127 & 179 & 92 & 76 & 67 & 144 & 200 & 139 & 190 & 44 \\
\hline Lira & 29 & 41 & 91 & 172 & 190 & 126 & 126 & 215 & 168 & 149 & 84 & 43 \\
\hline Makerere & 51 & 62 & 113 & 182 & 140 & 75 & 50 & 86 & 101 & 109 & 114 & 97 \\
\hline Masindi & 32 & 56 & 107 & 162 & 146 & 97 & 109 & 137 & 141 & 147 & 122 & 48 \\
\hline Mbarara & 45 & 64 & 96 & 123 & 78 & 23 & 20 & 61 & 95 & 105 & 120 & 75 \\
\hline Moroto & 10 & 27 & 72 & 120 & 121 & 71 & 122 & 94 & 51 & 47 & 49 & 25 \\
\hline Mubende & 32 & 70 & 160 & 178 & 89 & 29 & 49 & 87 & 120 & 106 & 82 & 67 \\
\hline Namulonge & 50 & 61 & 131 & 145 & 116 & 68 & 59 & 90 & 129 & 129 & 111 & 78 \\
\hline Ntusi & 36 & 53 & 96 & 103 & 97 & 24 & 36 & 105 & 127 & 136 & 152 & 72 \\
\hline Serere & 29 & 28 & 115 & 190 & 192 & 72 & 79 & 123 & 149 & 151 & 123 & 48 \\
\hline Soroti & 32 & 56 & 107 & 162 & 146 & 97 & 109 & 137 & 141 & 147 & 122 & 48 \\
\hline Tororo & 55 & 78 & 138 & 225 & 224 & 108 & 96 & 118 & 111 & 125 & 109 & 78 \\
\hline wedalai & 47 & 45 & 165 & 159 & 158 & 137 & 157 & 168 & 184 & 184 & 213 & 160 \\
\hline
\end{tabular}


scaling [7] [18]; gamma quantile mapping [7]; generalized quantile mapping [7] [16] [19]; and power transformation [7], among others. This study has adopted the generalized quantile mapping method to examine any potential improvement in the skill as simulated by the WRF model with different initial conditions based on the different RCPs (i.e. RCP4.5, RCP6.0 \& RCP8.5). Quantitle mapping has been proposed by [19] and presented using Equation 6. This method is also used and promoted by [14] while assessing the changes in precipitation and temperature over the Teesta River basin in the Indian Himalayan region under climate change.

$$
p^{*}=p_{r c p} \times\left[\overline{\frac{\overline{p_{o b s}}}{\overline{p_{r c p}}}}\right]
$$

where $p^{*}$ is the bias corrected precipitation estimate from the model; $p_{r c p}$ is the direct model output without bias correction and $p_{o b s}$ is the observed precipitation and $\overline{p_{o b s}}$ and $\overline{p_{r c p}}$ are the mean values of $p_{o b s}$ and $p_{r c p}$ respectively.

\section{Results and Discussion}

\subsection{The Temporal Performance of the WRF Model for the Different RCPs}

The performance of RCPs on monthly, seasonal and annual time scales is presented using Figure 3 and Figure 4. These figures show the temporal simulation performance of WRF being driven by the different RCPs i.e. RCP4.5, RCP6.0 and RCP8.5 compared with the observed patterns. Figure 3 is for the monthly trends over the study period i.e. 2006-2018 and Figure 4 is for the annual (Figure 4(a) \& Figure 4(b)) and seasonal trends i.e. March-May (Figure 4(c) \& Figure 4(d)) and September-November (Figure 4(e) \& Figure 4(f)) over the study period.

The performance of the WRF model pre-processed with different RCPs on monthly scale as presented by Figure 3 is generally poor and shows a negligible overall correlation i.e. of magnitudes less than 0.200 . Some isolated overestimates are observed especially around 2016 and 2018. The results further show that the RCPs can overestimate the monthly rainfall to magnitudes in excess of about $400 \%$ for RCP 8.5 ; RCP 4.5 overestimates up to about $360 \%$ while RCP6.0 estimated up to $240 \%$ of the long-term mean. A critical analysis of Figure 3 shows that $36.7 \%$ of observed monthly rainfall were below long-term mean; $63.3 \%$ for RCP4.5; 58.3\% for RCP6.0; and 57.5\% for RCP8.5. This suggested that the RCPs largely underestimated monthly rainfall over the study period. It is this underestimation that resulted in a smaller overall relative anomaly of $-3.956 \%$ for RCP4.5; $1.265 \%$ for RCP6.0; and 4.870\% for RCP8.5. A detailed performance for each of the stations used is presented using Figure 5.

Additional analysis of annual rainfall patterns revealed that the RCPs largely underestimate annual rainfall totals (Figure 4(a)). This performance however improves slightly with bias correction (Figure 4(b)). Further analysis of the re- 
sults for seasonal performance i.e. Figure 4(c) \& Figure 4(d) for the March-May rainfall season reveals that generally RCP4.5 and RCP8.5 underestimated the March-May rainfall over the study period with exception of RCP6.0. A slight increasing trend of the total March-May rainfall amount is observed at about 1.93\% over the period and a coefficient of variation of 2.4 is observed. Whereas RCP8.5 reasonably reproduced this trend, it had the largest variability i.e. coefficient of variation of 7.3. Additional analysis of the September-November results (Figure 4 (e) \& Figure 4(f)) also revealed an increasing trend of about $1.43 \%$ over the period. The performance of RCPs during this period largely overestimated the seasonal rainfall. RCP4.5 has the smallest relative anomaly i.e. 4.984 but comparatively a higher variability, i.e. 12.8. On the other hand, RCP6.0 has the highest anomaly but a comparatively smaller variability, i.e. 7.1.
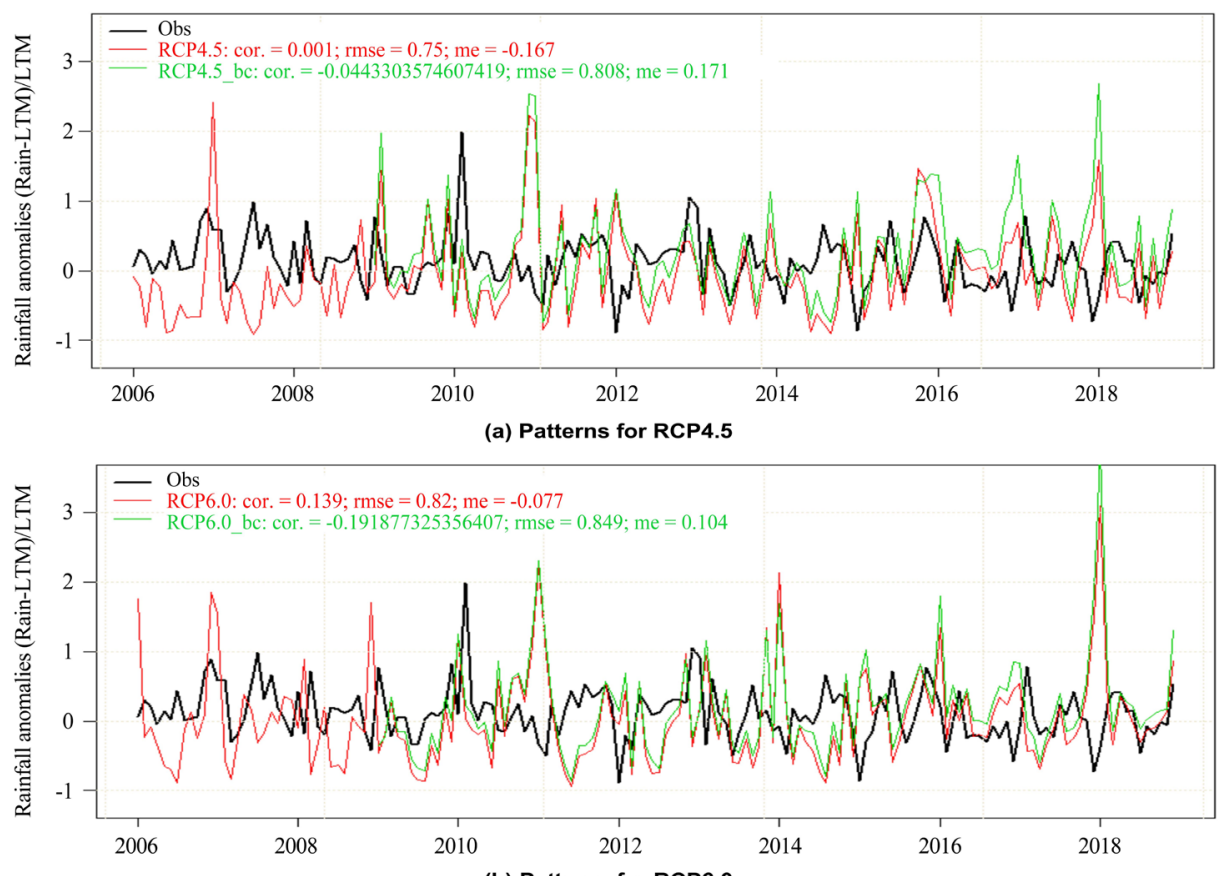

(b) Patterns for RCP6.0

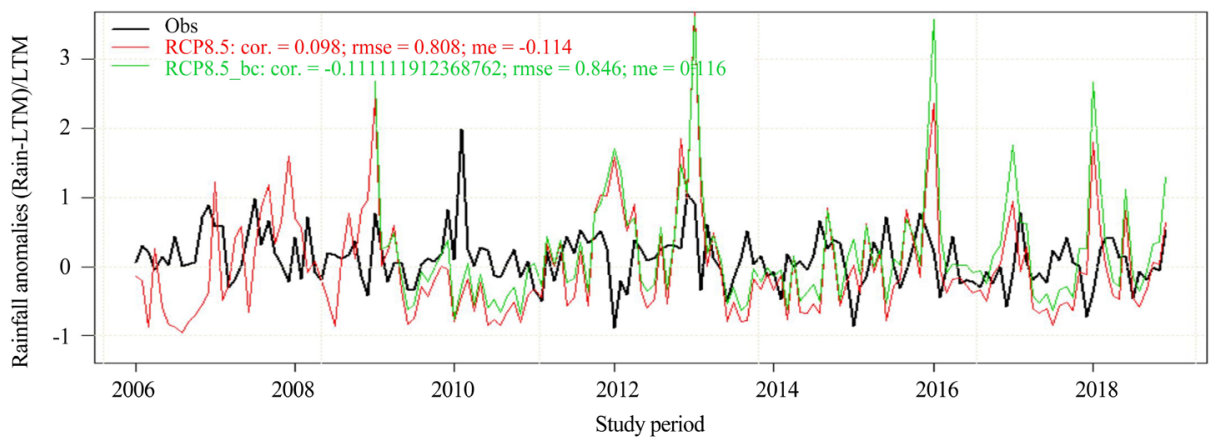

(c) Patterns for RCP8.5

Figure 3. Temporal patterns of RCPs simulated monthly rainfall and observed rainfall. The scale of the vertical axis is for relative rainfall anomalies computed from simulated/observed rainfall less the long-term mean (LTM) and then divided by LTM. Positive values indicate overestimation above the LTM while negative values indicate underestimation of the LTM. They have been presented along with observed rainfall for comparison. 

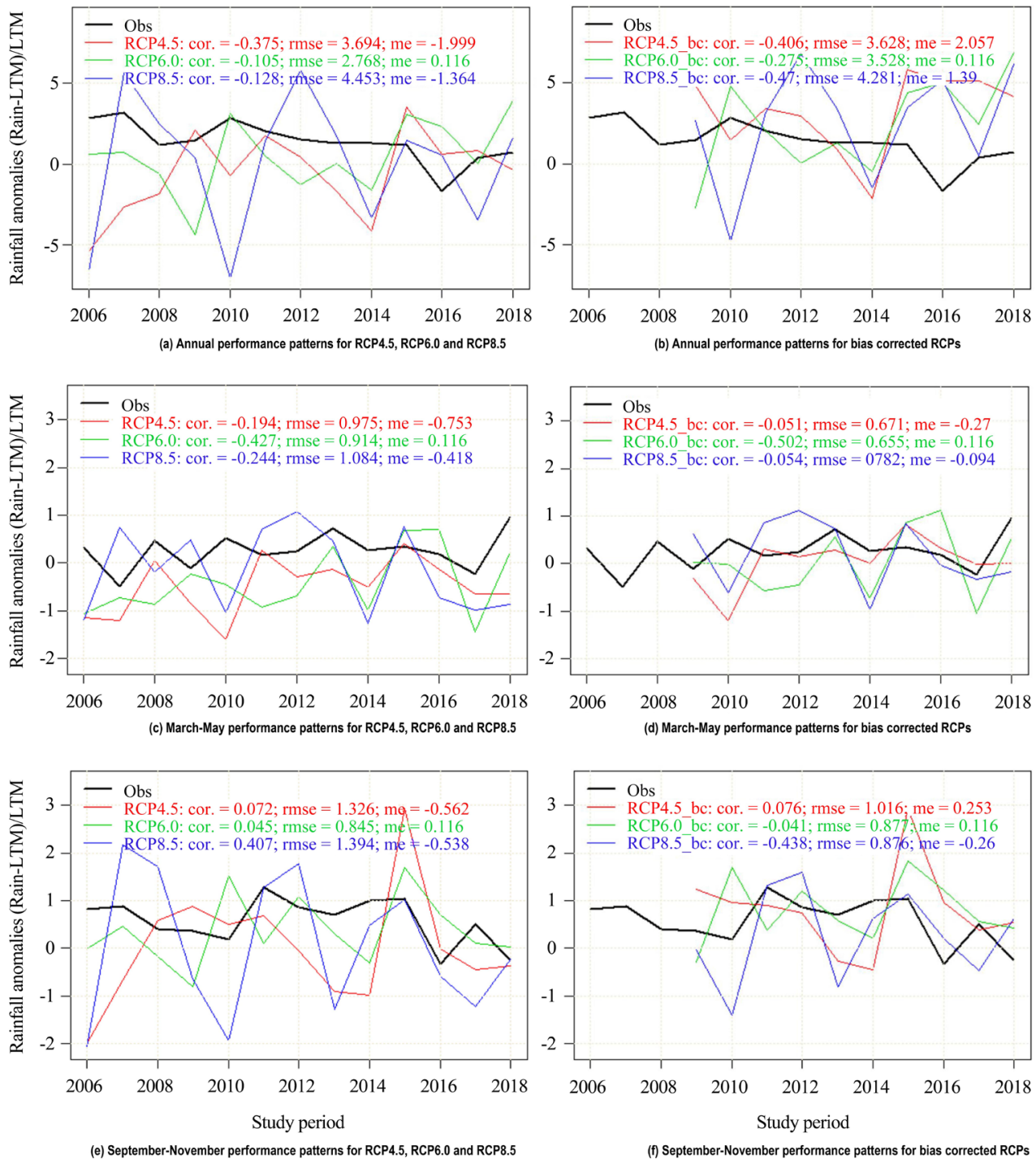

Figure 4. Temporal patterns of RCPs nationally averaged simulated seasonal rainfall and observed rainfall anomalies. ( $\&$ b) is for the performance on annual time scales; (c \& d) is for the March-May rainfall season while (e \& $\mathrm{f}$ ) is for the September-November Season over the study period.

The results in this study are comparable to the findings of Ongoma et al. [3] over East Africa. They evaluated 22 models under the CMIP5 and found the models to have a comparatively lower skill over East Africa while Fotso-Nguemo et al. [27] found RCP8.5 to present rainfall magnitudes comparatively lower than the Global Precipitation Climatology Center (GPCC) and Tropical Rainfall Measuring Mission (TRMM). While using RCP4.5 and RCP8.5 and 10 GCMs along with linear scaling as the bias correction method, Myo et al. [18] found that these RCPs projected fluctuating average monthly precipitation but found that annual precipitation is likely going to increase. These results are consistent with our findings which make us conclude that the $21^{\text {st }}$ century precipitation is going to be highly variable at monthly scale. 


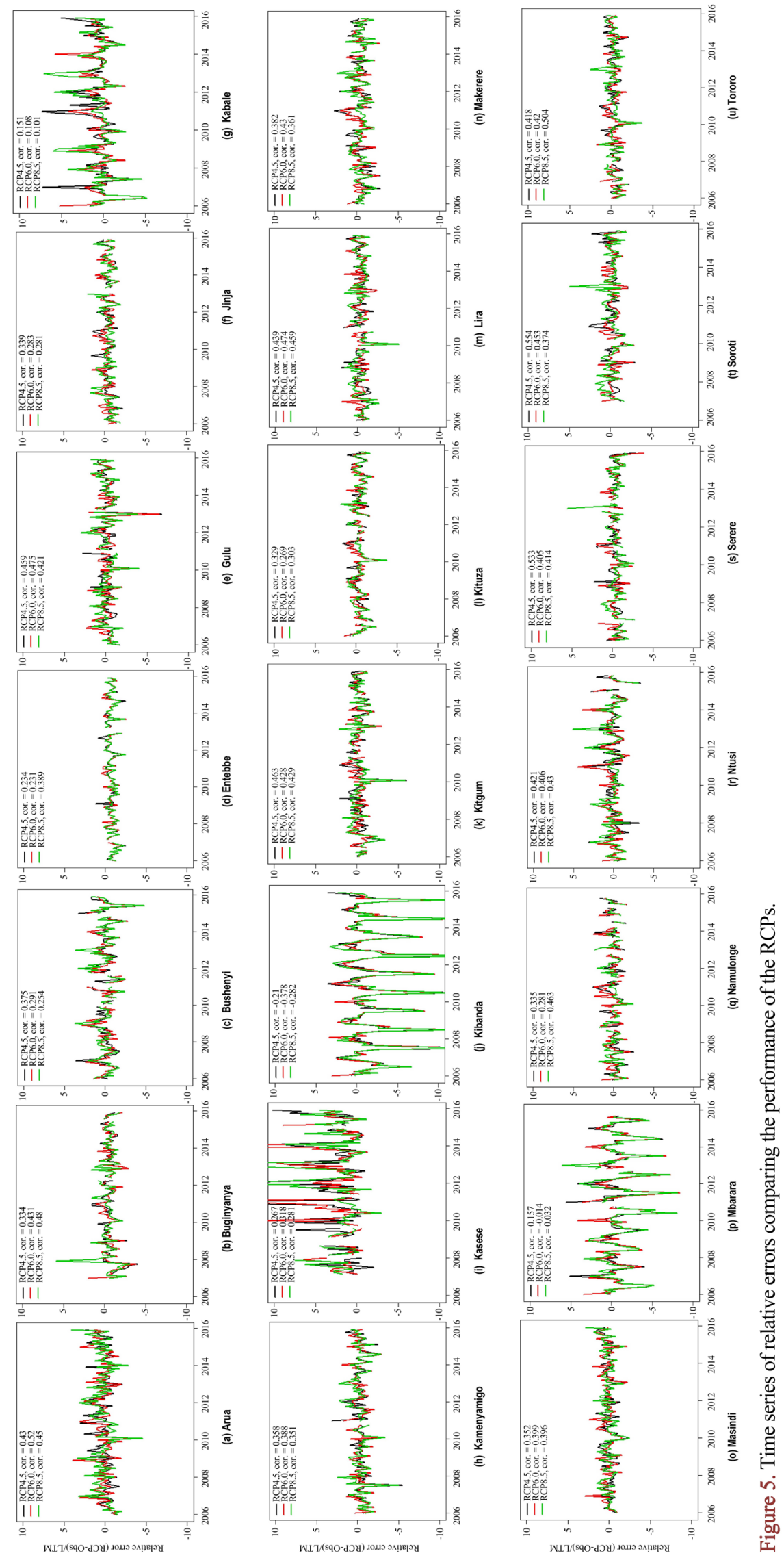




\subsection{Spatial Performance of the RCPs}

The spatial performance of WRF model driven by the three RCPs (RCP4.5, RCP6.0 \& RCP8.5) considered in this study along with the bias corrected output using quantile mapping is presented using Figures 6-8. These figures are for correlation analysis (Figure 6); relative mean error (Figure 7), and relative root mean square error (Figure 8). Additional analysis is presented using Tables 4-6 which present results per study location for correlation (Table 4); relative mean error (Table 5) and relative root mean square error (Table 6).

Table 4. Shows the correlation values at specific study locations. "Non bc" is direct model output without bias correction.

\begin{tabular}{|c|c|c|c|c|c|c|}
\hline & \multicolumn{3}{|c|}{ Non bc } & \multicolumn{3}{|c|}{ Bias corrected } \\
\hline & RCP 4.5 & RCP6.0 & RCP8.5 & RCP4.5 & RCP6.0 & RCP8.5 \\
\hline Arua & -0.07 & -0.17 & -0.23 & -0.08 & -0.21 & -0.25 \\
\hline Buginyanya & -0.03 & -0.12 & 0.05 & 0.03 & -0.12 & 0.13 \\
\hline Bushenyi & 0.01 & 0.03 & 0.03 & 0.01 & 0.02 & 0.03 \\
\hline Entebbe & -0.02 & -0.04 & 0.07 & 0.04 & -0.01 & 0.15 \\
\hline Gulu & 0.12 & 0.13 & 0.31 & 0.37 & 0.28 & 0.49 \\
\hline Jinja & 0.03 & -0.10 & -0.04 & 0.02 & -0.17 & 0.03 \\
\hline Kabale & -0.07 & -0.07 & -0.01 & -0.07 & -0.07 & -0.01 \\
\hline Kakoge & -0.13 & 0.27 & 0.33 & -0.40 & 0.29 & 0.25 \\
\hline Kamenyamigo & -0.07 & 0 & 0.06 & -0.11 & -0.01 & 0.10 \\
\hline kasese & 0.03 & -0.08 & 0.07 & -0.03 & -0.12 & -0.03 \\
\hline Kibanda & -0.16 & -0.23 & 0 & -0.13 & -0.16 & 0.05 \\
\hline kitgum & -0.18 & -0.15 & -0.16 & -0.29 & -0.21 & -0.17 \\
\hline Kituza & 0.03 & -0.11 & 0.02 & 0.04 & -0.10 & 0.10 \\
\hline Kotido & -0.01 & -0.07 & 0.43 & 0.06 & -0.08 & 0.45 \\
\hline Kyembogo & 0.11 & 0.01 & -0.11 & 0.09 & 0.01 & -0.14 \\
\hline Kyenjojo & -0.05 & 0.03 & -0.02 & -0.06 & 0.04 & -0.03 \\
\hline Lira & -0.10 & 0.11 & 0.04 & -0.08 & -0.04 & 0.04 \\
\hline Makerere & 0.21 & 0.23 & 0.29 & 0.15 & 0.08 & 0.19 \\
\hline Masindi & 0.16 & 0.05 & -0.10 & 0.13 & -0.02 & -0.07 \\
\hline Mbarara & -0.18 & -0.20 & 0 & -0.24 & -0.26 & -0.01 \\
\hline Moroto & -0.06 & -0.21 & 0.44 & -0.10 & -0.21 & 0.36 \\
\hline Mubende & -0.08 & -0.06 & -0.09 & -0.08 & -0.06 & -0.09 \\
\hline Namulonge & -0.02 & -0.08 & 0.21 & 0.02 & -0.13 & 0.26 \\
\hline Ntusi & -0.07 & -0.05 & 0 & -0.12 & -0.10 & -0.04 \\
\hline Serere & 0.14 & -0.07 & 0.16 & 0.15 & -0.03 & 0.22 \\
\hline Soroti & 0.14 & -0.06 & 0.16 & 0.03 & -0.18 & 0.18 \\
\hline Tororo & -0.13 & -0.12 & -0.01 & -0.10 & -0.11 & 0.03 \\
\hline Wedalai & 0.16 & -0.10 & -0.35 & 0.22 & 0.05 & -0.36 \\
\hline Average & -0.01 & -0.04 & 0.06 & -0.02 & -0.06 & 0.07 \\
\hline
\end{tabular}


Table 5. Shows relative mean error magnitudes as a percentage of the long-term mean. "DMO" is direct model output i.e. not corrected for bias.

\begin{tabular}{|c|c|c|c|c|c|c|}
\hline & \multicolumn{3}{|c|}{ Mean Error (DMO) } & \multicolumn{3}{|c|}{ Mean Error (Bias corrected) } \\
\hline & $\mathrm{RCP} 4.5$ & RCP6.0 & RCP8.5 & RCP4.5 & RCP6.0 & RCP8.5 \\
\hline Arua & 0.09 & 0.24 & 0.34 & 0.31 & 0.27 & 0.34 \\
\hline Buginyanya & -0.48 & -0.37 & -0.36 & 0.33 & 0.35 & 0.24 \\
\hline Bushenyi & 0.20 & 0.15 & 0.11 & 0.13 & 0.02 & -0.01 \\
\hline Entebbe & -0.79 & -0.76 & -0.82 & 0.24 & 0.21 & 0.18 \\
\hline Gulu & -0.43 & -0.32 & -0.27 & 0.06 & 0.02 & 0.19 \\
\hline Jinja & -0.32 & -0.25 & -0.32 & 0.11 & 0.02 & 0.03 \\
\hline kabale & 0.03 & 0.04 & 0.16 & 0.12 & 0 & 0.04 \\
\hline Kakoge & -0.16 & -0.18 & -0.36 & 0.08 & 0.16 & 0.16 \\
\hline Kamenyamigo & -0.20 & -0.16 & -0.19 & 0.08 & 0.01 & -0.06 \\
\hline Kasese & 2.00 & 2.35 & 2.06 & 0.15 & 0.14 & 0.03 \\
\hline Kibanda & -0.05 & -0.07 & -0.06 & 0.22 & 0.10 & 0.07 \\
\hline Kitgum & -0.25 & -0.10 & -0.08 & 0.36 & 0.42 & 0.40 \\
\hline Kituza & -0.59 & -0.57 & -0.61 & 0.08 & -0.01 & -0.03 \\
\hline Kotido & 0.89 & 1.85 & 0.01 & 1.51 & 1.39 & 0.70 \\
\hline Kyembogo & 0.36 & 0.62 & 0.51 & 0.30 & 0.53 & 0.66 \\
\hline Kyenjojo & 0.53 & 0.63 & 0.52 & 0.16 & 0.15 & 0.29 \\
\hline Lira & -1.11 & -0.95 & -1.00 & 0.29 & 0.27 & 0.32 \\
\hline Makerere & -0.38 & -0.33 & -0.4 & 0.17 & 0.06 & 0.06 \\
\hline Masindi & -0.29 & -0.11 & -0.19 & 0.04 & -0.01 & 0.06 \\
\hline Mbarara & -0.08 & -0.09 & -0.06 & 0.20 & 0.06 & 0.04 \\
\hline Moroto & -0.38 & 0.09 & -0.4 & 0.94 & 0.73 & 0.82 \\
\hline Mubende & 0.59 & 0.62 & 0.52 & 0.14 & 0.08 & 0.18 \\
\hline Namulonge & -0.06 & 0.04 & -0.03 & 0.08 & 0.01 & 0.01 \\
\hline Ntusi & 0.11 & 0.21 & 0.14 & 0.19 & 0.11 & 0.09 \\
\hline Serere & -0.41 & -0.36 & -0.36 & 0.23 & 0.16 & 0.22 \\
\hline Soroti & -0.28 & -0.22 & -0.19 & 0.11 & 0.08 & 0.04 \\
\hline Tororo & -0.32 & -0.21 & -0.25 & 0.26 & 0.22 & 0.20 \\
\hline Wedalai & -0.08 & 0.01 & 0.03 & 0 & 0.03 & 0.19 \\
\hline Average & -0.07 & 0.06 & -0.06 & 0.25 & 0.20 & 0.20 \\
\hline
\end{tabular}


Table 6. Shows the relative RMSE over different study locations as a fraction of the long-term mean.

\begin{tabular}{|c|c|c|c|c|c|c|}
\hline & \multicolumn{3}{|c|}{ RMSE (\% of LTM) } & \multicolumn{3}{|c|}{ RMSE (Bias corrected) } \\
\hline & $\mathrm{RCP} 4.5$ & RCP6.0 & RCP8.5 & RCP4.5 & RCP6.0 & RCP8.5 \\
\hline Arua & 1.07 & 1.17 & 1.64 & 1.18 & 1.2 & 1.65 \\
\hline Buginyanya & 1.14 & 1.32 & 1.19 & 1.49 & 1.82 & 1.37 \\
\hline Bushenyi & 1.16 & 0.98 & 1.04 & 0.9 & 0.83 & 0.86 \\
\hline Entebbe & 1.04 & 1.03 & 1.03 & 1.07 & 1.03 & 0.89 \\
\hline Gulu & 1.26 & 1.23 & 1.19 & 1.24 & 1.29 & 1.41 \\
\hline Jinja & 0.77 & 0.79 & 0.82 & 0.76 & 0.76 & 0.74 \\
\hline Kabale & 1.5 & 1.29 & 1.56 & 0.9 & 0.84 & 0.84 \\
\hline Kakoge & 0.58 & 0.54 & 0.51 & 0.49 & 0.63 & 0.60 \\
\hline Kamenyamigo & 1.01 & 0.95 & 0.96 & 1.06 & 1.01 & 0.96 \\
\hline Kasese & 3.82 & 4.73 & 3.88 & 1.23 & 1.48 & 1.22 \\
\hline Kibanda & 1.24 & 1.2 & 1.14 & 1.28 & 1.16 & 1.11 \\
\hline Kitgum & 1.3 & 1.53 & 1.79 & 1.57 & 1.79 & 2.01 \\
\hline Kituza & 0.98 & 1 & 1.01 & 0.91 & 0.94 & 0.89 \\
\hline Kotido & 2.58 & 4.61 & 0.99 & 3.71 & 4.31 & 1.82 \\
\hline Kyembogo & 1.2 & 1.68 & 1.79 & 1.15 & 1.56 & 2 \\
\hline Kyenjojo & 1.18 & 1.27 & 1.3 & 0.9 & 0.87 & 1.11 \\
\hline Lira & 1.71 & 1.59 & 1.65 & 1.79 & 1.8 & 1.92 \\
\hline Makerere & 0.96 & 0.93 & 0.96 & 1.02 & 1.01 & 0.99 \\
\hline Masindi & 0.82 & 0.91 & 0.96 & 0.82 & 0.88 & 0.96 \\
\hline Mbarara & 1.54 & 1.38 & 1.38 & 1.44 & 1.31 & 1.16 \\
\hline Moroto & 1.43 & 2.7 & 1.3 & 2.98 & 3.92 & 3.01 \\
\hline Mubende & 1.25 & 1.2 & 1.33 & 0.91 & 0.8 & 1.02 \\
\hline Namulonge & 0.86 & 0.92 & 0.83 & 0.8 & 0.85 & 0.75 \\
\hline Ntusi & 1.13 & 1.15 & 1.12 & 1.05 & 1.02 & 1.02 \\
\hline Serere & 0.96 & 1.02 & 1.02 & 1.15 & 1.19 & 1.24 \\
\hline Soroti & 0.88 & 1 & 0.98 & 0.99 & 1.08 & 0.96 \\
\hline Tororo & 1.14 & 1.26 & 1.17 & 1.22 & 1.27 & 1.18 \\
\hline Wedalai & 0.43 & 0.5 & 0.77 & 0.48 & 0.54 & 1.11 \\
\hline Average & 1.25 & 1.42 & 1.26 & 1.23 & 1.33 & 1.24 \\
\hline
\end{tabular}



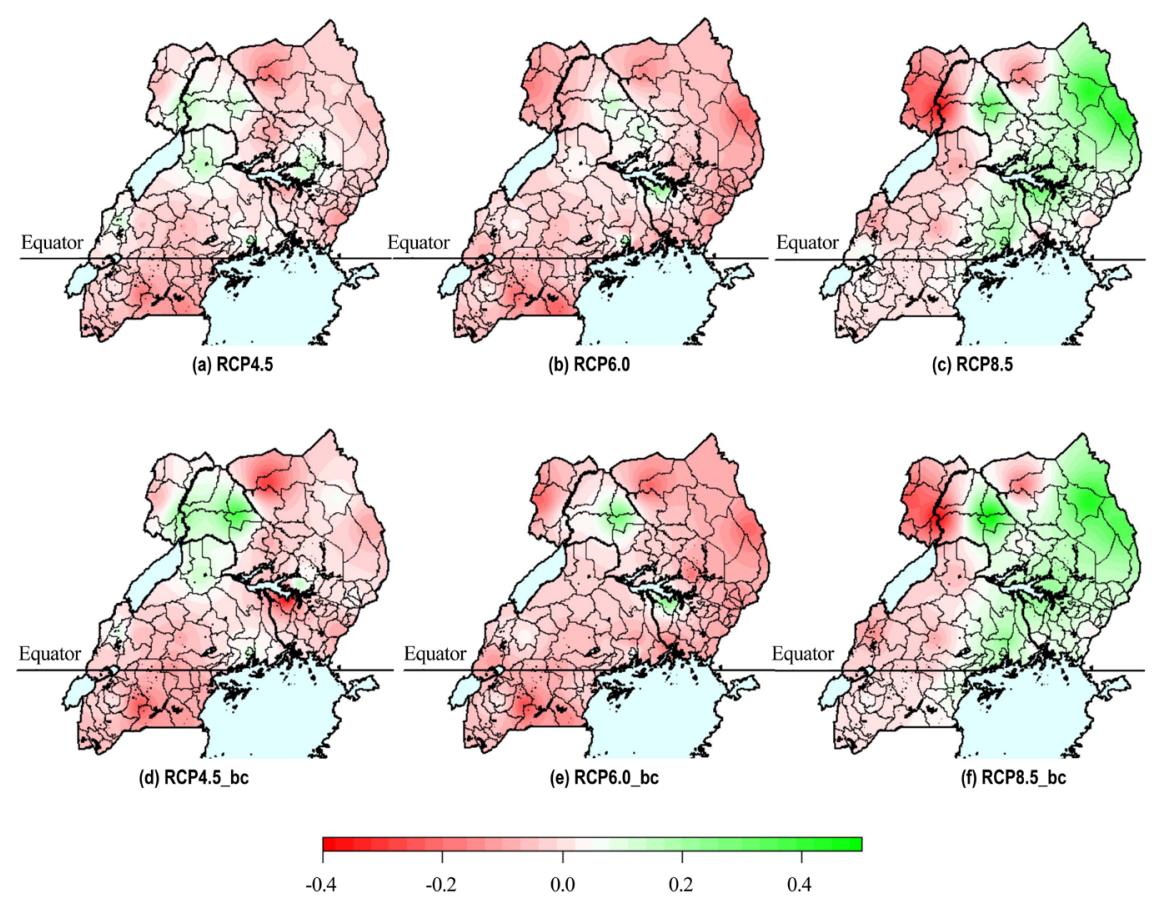

Pearson correlation scores of observed rainfall in $\mathrm{mm}$ and simulated rainfall in $\mathrm{mm}$

Figure 6. Spatial correlation of RCPs simulated rainfall and observed rainfall. Figures $(a-c)$ are for the direct model output without bias correction while Figures (d-f) are for bias corrected model output.
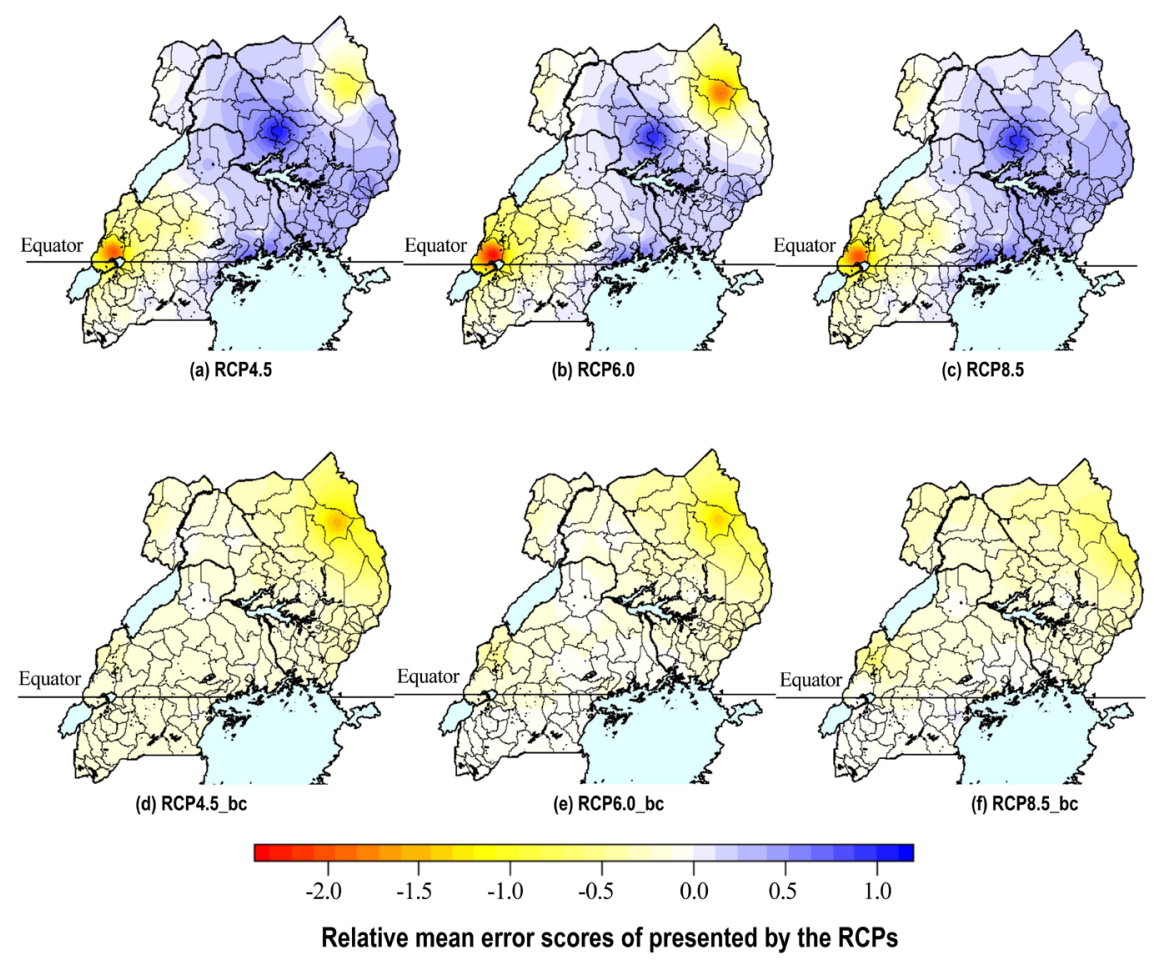

Figure 7. Shows the spatialized relative mean errors presented by the RCPs as a fraction of the long-term mean. Figures $(\mathrm{a}-\mathrm{c}$ ) are the relative mean errors for the RCPs with no bias correction while figures (d-f) are the relative mean errors for the RCPs with bias correction. 

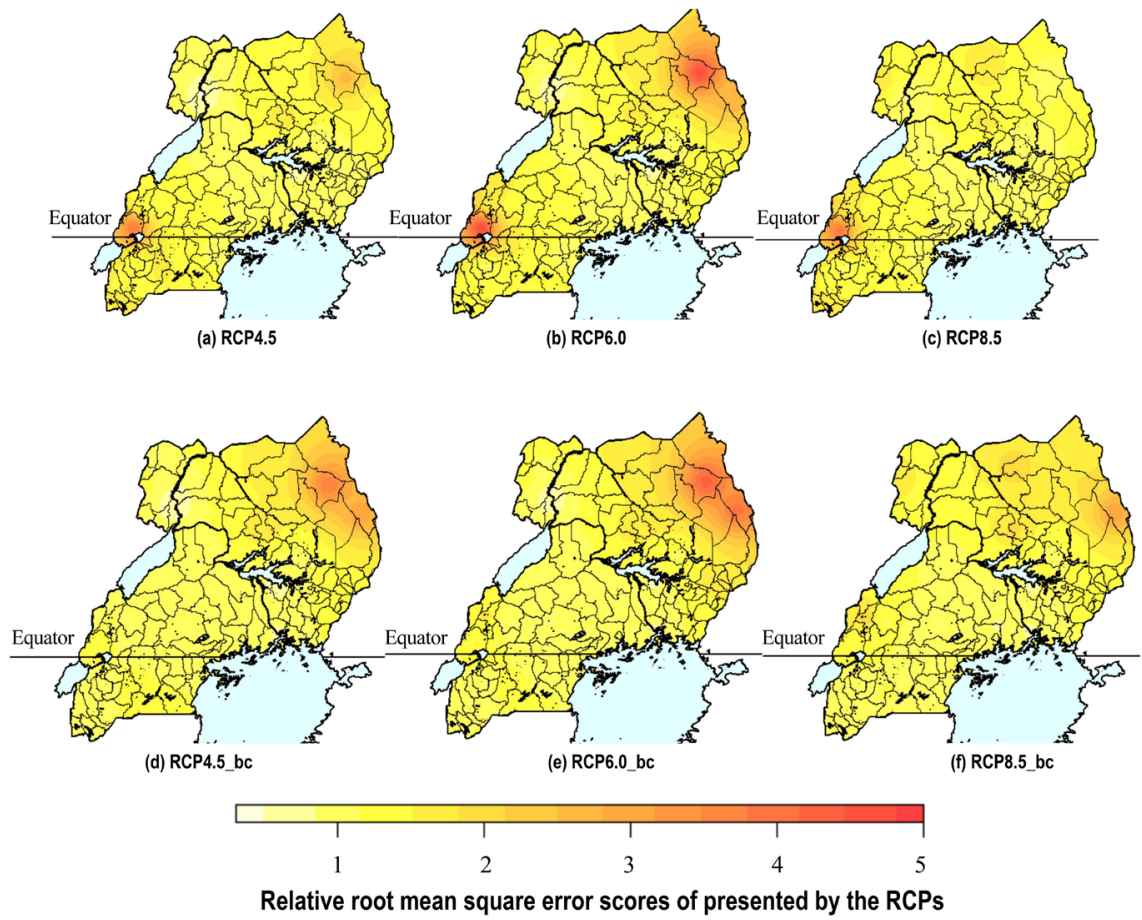

Figure 8. Shows the spatialized relative root mean square errors presented by the RCPs as a fraction of the long-term mean. Figures $(\mathrm{a}-\mathrm{c})$ are the relative root mean square errors for the RCPs without bias correction while figures (d-f) are the relative root mean square errors for the RCPs with bias correction.

Analysis of Figure 6 shows that nearly all the RCPs presented a weak negative correlation over most places of the country. A slight improvement with bias correction is noted over north western with RCP8.5 but largely, RCP4.5 and RCP6.0 presented a negative correction. RCP8.5 had a weak negative correlation on the western part of the country and a slight positive correction on the eastern part of the country. There seems to be no noticeable improvement with bias correction especially for RCP8.5. Additional analysis of the correlation values at specific locations (Table 4) reveals generally that RCP4.5 and RCP6.0 largely presented a negative correlation with observed rainfall i.e. RCP4.5 (17 cases out of 28 cases as negative correlation values) and RCP6.0 (19 cases out of 28 cases as negative values). Generally, these are very low scores and can not explain the variation in observed rainfall.

Additional analysis is carried out on results presented by Figure 7 which presents the spatialized relative mean errors. The results show that RCPs with no bias correction had a greater part of the country with a slight overestimate especially RCP4.5 i.e. with magnitudes $0-1.0$ of the long-term mean. For all the RCPs, the southwestern region is underestimated. A further investigation of relative mean errors presented by the bias corrected model output (Figures $7(\mathrm{~d})-(\mathrm{f})$ ) reveals that largely areas that were originally overestimated are now underestimated. Areas that were originally underestimated have the relative mean errors slightly improved e.g. the case of south western region. Generally 
the relative mean error magnitudes for both bias corrected and direct model output remain comparatively small largely within -0.9 to 1.0 of the long-term mean. This is also observed from the performance at specific study locations presented using Table 5. A detailed analysis of the results presented in Table 5 reveals that bias correction had a tendency of removing the underestimation to become overestimation over most of locations i.e. 23 out of 28 ; 19 out of 28 ; and 21 out of 28 for RCPs 4.5; 6.0; and 8.5 respectively. In a related study by Ghimire et al. [15], they noted that bias correction reduces the overall error magnitudes. This is why the relative mean error appears positive on average in Table 5. This could also be the reason why the bias corrected results presented comparatively better performance in Figure 3 and Figure 4.

A further investigation of the relative magnitudes of errors compared to the long-term mean carried out using the relative root mean square error (Equation (2)) and presented using Figure 8 confirms the results presented in Figure 7. Generally, the magnitude of errors is approximately of magnitude 1.0 to 2.5 with exception of southwestern Uganda where they largely appear greater than 1.5 of the long-term mean especially over Mt. Rwenzori region. Additionally RCP6.0 and the bias corrected RCP4.5 and RCP6.0 appear to present comparatively larger error magnitudes of the north eastern region. A slight improvement in the magnitudes of relative root mean square errors over the south western region especially Mt. Rwenzori area is noted in all bias corrected RCP products. This is also confirmed by the results presented at specific locations in Table 6 which presents a slight improvement in the error magnitudes. A detailed analysis of the absolute root mean square errors in comparison to the long-term mean is presented using Table 6. A poor performance is noted over Kasese, Lira, Moroto and Mbarara (Table 6) of order of magnitude generally greater than 1.5 of the long-term mean especially the bias corrected results. Overall the results show that RCP4.5 presented a slightly better performance.

The foregoing results probably indicate that these RCPs may not be realistically valid in low latitudes. However, a study over Central Africa with the domain including Uganda, by Fotso-Nguemo et al. [27] noted that the ensemble mean of the $20 \mathrm{GCMs}$ was able to reproduce the rainfall patterns exhibited by the Global Precipitation Climatology Center better than those presented by the Tropical Rainfall Measuring Mission. This suggests different performance scores of RCPs with different data-sets and thus underscores the importance of using station observations as ground truth in validation studies. Nonetheless, the RCPs fairly reproduces the temporal patterns (Figure 3 and Figure 4) albeit with an underestimation. This could suggest that future extreme events being projected by different studies under these RCPs could be underestimated and could actually be severe. To improve the performance of the RCPs, this study proposes data assimilation or review of these RCPs.

\subsection{Skill Scores}

Figure 9 presents the spatialized accuracy in terms of the hit rate (accuracy) for 
the RCPs while Table 7 presents the hit rate levels per study location. The results generally show RCP8.5 presenting a slightly better skill than the rest. Isolated cases of above average skill are observed over the northwestern and northeastern regions. However, generally the skill is largely $20 \%-50 \%$. There was no noticeable improvement in skill with bias correction of the RCPs. In some cases over some areas, actually the skill degraded e.g. over the northeastern Uganda. This is in contrast to the findings of Ghimire et al. [15], who noted that bias correction improves the accuracy of numerical simulations. This study argues that the weak/no improvement in the performance after bias correction could be because the initial conditions used to initialize this study are already bias corrected as described by Monaghan et al. [17], and so additional bias correction is not necessary.

Further to the skill scores (Figure 9 and Table 7), the results are in agreement with Kisembe et al. [9], who noted that the climate simulations whereas they reproduce the climate variability, they present a poor skill regarding the rainfall seasons especially the March-May rainfall season over Uganda. In general, this study finds RCP8.5 to present a slightly better performance in terms of the hit rate and is thus proposed for future simulation over low latitudes including Uganda. However it is surprising to note that bias correction did not necessary improve performance and probably considers that this observation could be that because the LBCs used in this experiment are already bias corrected as explained earlier.
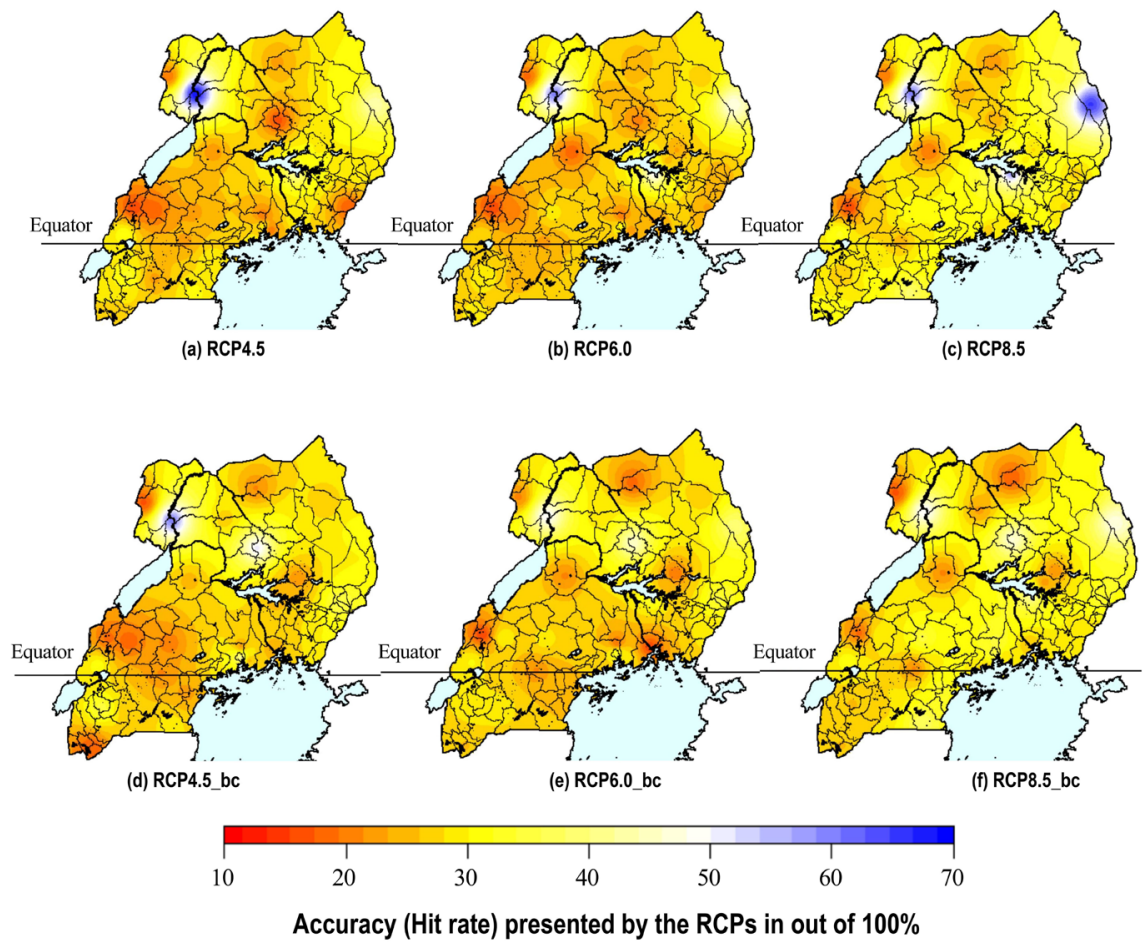

Figure 9. Shows the Spatial accuracy in terms of the hit rate presented by the RCPS. Figures $(\mathrm{a}-\mathrm{c})$ are for the direct model output as simulated by the RCPs while Figures (d-f) are for the bias corrected hit rates of the RCPS. The results shown are out of $100 \%$ 
Table 7. Shows the results of hit rates for the RCPs. "DMO" is direct model output with no bias correction.

\begin{tabular}{|c|c|c|c|c|c|c|}
\hline & \multicolumn{3}{|c|}{ HIT rate, DMO (\%) } & \multicolumn{3}{|c|}{ HIT rate (Bias corrected) } \\
\hline & $\mathrm{RCP} 4.5$ & RCP6.0 & RCP8.5 & RCP4.5_bc & RCP6.0_bc & RCP8.5_bc \\
\hline Arua & 20.00 & 18.71 & 19.35 & 16.81 & 21.01 & 16.81 \\
\hline Buginyanya & 28.47 & 24.09 & 27.01 & 35.96 & 34.21 & 32.46 \\
\hline bushenyi & 32.31 & 29.23 & 26.15 & 34.74 & 29.47 & 25.26 \\
\hline Entebbe & 29.25 & 27.89 & 29.25 & 29.46 & 25.00 & 25.89 \\
\hline Gulu & 27.52 & 24.16 & 23.49 & 26.55 & 28.32 & 23.01 \\
\hline Jinja & 29.33 & 23.33 & 28.67 & 23.68 & 15.79 & 25.44 \\
\hline Kabale & 27.33 & 28.00 & 31.33 & 17.54 & 25.44 & 25.44 \\
\hline Kakoge & 41.67 & 50.00 & 58.33 & 25.00 & 33.33 & 41.67 \\
\hline Kamenyamigo & 29.60 & 25.60 & 30.4 & 22.73 & 23.64 & 32.73 \\
\hline Kasese & 31.37 & 26.8 & 32.03 & 30.77 & 29.91 & 30.77 \\
\hline Kibanda & 30.46 & 25.83 & 38.41 & 29.06 & 25.64 & 37.61 \\
\hline Kitgum & 22.97 & 24.32 & 22.30 & 21.24 & 18.58 & 17.70 \\
\hline Kituza & 19.86 & 21.92 & 26.03 & 25.00 & 28.57 & 27.68 \\
\hline Kotido & 30.00 & 26.67 & 33.33 & 26.67 & 26.67 & 30.00 \\
\hline Kyembogo & 15.62 & 15.62 & 15.62 & 18.75 & 15.62 & 18.75 \\
\hline Kyenjojo & 17.65 & 20.59 & 26.47 & 17.65 & 29.41 & 29.41 \\
\hline Lira & 16.56 & 20.53 & 23.84 & 50.86 & 45.69 & 46.55 \\
\hline Makerere & 28.67 & 31.33 & 31.33 & 41.23 & 33.33 & 35.96 \\
\hline Masindi & 22.22 & 18.06 & 19.44 & 24.77 & 21.10 & 21.10 \\
\hline Mbarara & 22.88 & 24.84 & 30.07 & 26.05 & 28.57 & 26.89 \\
\hline Moroto & 43.48 & 47.83 & 65.22 & 30.43 & 39.13 & 47.83 \\
\hline Mubende & 22.86 & 28.57 & 31.43 & 20.00 & 28.57 & 34.29 \\
\hline Namulonge & 19.57 & 19.57 & 31.88 & 23.08 & 19.23 & 34.62 \\
\hline Ntusi & 22.86 & 22.86 & 24.29 & 21.15 & 21.15 & 21.15 \\
\hline Serere & 30.20 & 24.83 & 28.86 & 23.48 & 24.35 & 22.61 \\
\hline Soroti & 29.58 & 23.24 & 27.46 & 21.85 & 19.33 & 21.85 \\
\hline Tororo & 17.81 & 23.29 & 27.40 & 29.82 & 28.07 & 28.07 \\
\hline Wedalai & 68.75 & 59.38 & 59.38 & 59.38 & 50.00 & 50.00 \\
\hline Average & 27.82 & 27.04 & 31.03 & 27.63 & 27.47 & 29.70 \\
\hline
\end{tabular}




\section{Summary and Conclusion}

This study was about validating the RCPs and was carried out over Uganda using 28 stations spread across the country for the period 2006-2018. It carried out bias correction for the RCPs over the period 2009-2018. The period 2006-2008 was for training the bias correction algorithm and the study used the quntile mapping method to correct the biases of the three RCPs i.e. RCP4.5, RCP6.0 and RCP8.5. In assessing the performance of the RCPs, the study used the Pearson correlation coefficient; the relative root mean square error; relative mean error; and accuracy (i.e. hit rate) computed from a $3 \times 3$ contingency table for the cases of "Below normal", "Normal", and "Above normal". Below normal is when the monthly rainfall is less than $75 \%$ of the long-term mean; Normal is when the monthly rainfall is within $75 \%-125 \%$ of the long-term mean; and Above normal is when the monthly rainfall is greater than $125 \%$ of the long-term mean. Trends are presented using line graphs while the spatial patterns are presented using maps derived using the inverse distance weighted spatialization method.

This study summarises the performance of the RCPs using Table 8. The summary shows that RCP8.5 presented comparatively better ranking on correlation score; relative mean error; relative root mean square error and hit rate. This was followed by RCP4.5 and then RCP6.0. However this study observed that there was no significant difference in the performance of all these RCPs and considers that they remain poor in informing us about future changes in climates especially over low latitudes.

The study further noted largely a negligible improvement due to bias correction. It noted that bias correction tended to improve underestimated rainfall cases and on the other hand decreased the overestimated rainfall cases. This did not necessarily improve the skill, nor the error magnitudes and we attribute this

Table 8. Summarizes the performance of the RCPs on different monthly time-scales. "RMSE" is the root mean square error. The values in the parenthesis are the ranking for the given score on the scale of 1 - 3 for the respective RCP. The lower the rank, the better the performance of the RCP. The average ranking is obtained by simple arithmetic average column-wise across different performance scores.

\begin{tabular}{ccccccc}
\hline & \multicolumn{5}{c}{ Scores (\%) } & \multicolumn{3}{c}{ Bias corrected } \\
\cline { 2 - 7 } & RCP4.5 & RCP6.0 & RCP8.5 & RCP4.5 & RCP6.0 & RCP8.5 \\
\hline $\begin{array}{c}\text { Performance } \\
\text { score }\end{array}$ & & & & & & \\
Correlation & $-0.01(2)$ & $-0.04(3)$ & $0.06(1)$ & $-0.02(2)$ & $-0.06(3)$ & $0.07(1)$ \\
$\begin{array}{c}\text { Relative mean } \\
\text { error }\end{array}$ & $-0.07(3)$ & $0.06(1)$ & $-0.06(1)$ & $0.25(3)$ & $0.20(1)$ & $0.20(1)$ \\
$\begin{array}{c}\text { Relative RMSE } \\
\begin{array}{c}\text { Hit rate } \\
\text { Average }\end{array}\end{array}$ & $1.25(1)$ & $1.42(3)$ & $1.26(1)$ & $1.23(1)$ & $1.33(3)$ & $1.24(2)$ \\
ranking & $27.82(2)$ & $27.04(3)$ & $31.03(1)$ & $27.63(2)$ & $27.47(3)$ & $29.70(1)$ \\
\hline
\end{tabular}


to the fact that, it could be because the LBCs are already bias-corrected. Whereas this study recommends RCP8.5, it also recommends re-evaluating the assumptions in these RCPs. The other option recommended is to use data assimilation to improve the analysis of these RCPs for future climate scenarios.

\section{Acknowledgements}

The authors acknowledge the financial support from the project "Tailoring climate services for improved agricultural production" granted by Makerere University and government of Uganda under the Research and Innovation fund to make this study open access. The authors further appreciate the technical support provided through the Climate Research for Development (CR4D) Postdoctoral Fellowship to the project: "The implications of the 1.5 - $2.0 \mathrm{deg}$. Temperature Celsius to Uganda's Climate, Agriculture and Water Nexus", project number CR4D-19-10 implemented by the African Academy of Sciences (AAS) in partnership with the United Kingdoms Department for International Development (DfID) Weather and Climate Information Services for Africa (WISER) programme and the African Climate Policy Center (ACPC) of the United Nations Economic Commission for Africa (UNECA). Statements made and views expressed in this work are solely the responsibility of the authors.

\section{Conflicts of Interest}

The authors declare no conflicts of interest regarding the publication of this paper.

\section{References}

[1] Tiyo, C.E., Orach-Meza, F.L. and Edroma, E.L. (2015) Understanding Small-Scale Farmers' Perception and Adaption Strategies to Climate Change Impacts: Evidence from Two Agro-Ecological Zones Bordering National Parks of Uganda. Journal of Agricultural Science, 7, 253-270. https://doi.org/10.5539/jas.v7n10p253

[2] Okonya, J.S., Syndikus, K. and Kroschel, J. (2013) Farmers' Perception of and Coping Strategies to Climate Change: Evidence from Six Agro-Ecological Zones of Uganda. Journal of Agricultural Science, 5, 252-262. https://doi.org/10.5539/jas.v5n8p252

[3] Ongoma, V., Chen, H. and Gao, C.J. (2019) Evaluation of Cmip5 Twentieth Century Rainfall Simulation over the Equatorial East Africa. Theoretical and Applied Climatology, 135, 893-910. https://doi.org/10.1007/s00704-018-2392-x

[4] Nyakaisiki, K., Mugume, I., Ngailo, T. and Nakabugo, R. (2019) The Use of Indigenous Knowledge in Predicting Changes in Seasonal Rainfall by Smallholder Farmers of Ruteete Subcounty, Kabarole District. Journal of Geoscience and Environment Protection, 7, 13-22. https://doi.org/10.4236/gep.2019.71002

[5] Agathe Ouedraogo, W.A., Gathenya, J.M. and Raude, J.M. (2019) Projecting Wet Season Rainfall Extremes Using Regional Climate Models Ensemble and the Advanced Delta Change Model: Impact on the Streamow Peaks in Mkurumudzi Catchment, Kenya. Hydrology, 6, 76. https://doi.org/10.3390/hydrology6030076

[6] Cools, J., Innocenti, D. and Obrien, S. (2016) Lessons from Flood Early Warning Systems. Environmental Science \& Policy, 58, 117-122. 
https://doi.org/10.1016/j.envsci.2016.01.006

[7] Noor, M., Ismail, T.B., Shahid, S., Ahmed, K., Chung, E.-S. and Nawaz, N. (2019) Selection of CMIP5 Multi-Model Ensemble for the Projection of Spatial and Temporal Variability of Rainfall in Peninsular Malaysia. Theoretical and Applied Climatology, 138, 999-1012. https://doi.org/10.1007/s00704-019-02874-0

[8] Giannini, A., Lyon, B., Seager, R. and Vigaud, N. (2018) Dynamical and Thermodynamic Elements of Modeled Climate Change at the East African Margin of Convection. Geophysical Research Letters, 45, 992-1000.

https://doi.org/10.1002/2017GL075486

[9] Kisembe, J., Favre, A., Dosio, A., Lennard, C., Geoffrey, S. and Nimusiima, A. (2019) Evaluation of Rainfall Simulations over Uganda in CORDEX Regional Climate Models. Theoretical and Applied Climatology, 137, 1117-1134. https://doi.org/10.1007/s00704-018-2643-x

[10] Opio, R., Sabiiti, G., Nimusiima, A., Mugume, I. and Sansa-Otim, J. (2020) Wrf Simulations of Extreme Rainfall over Ugandas Lake Victoria Basin: Sensitivity to $\mathrm{Pa}$ rameterization, Model Resolution and Domain Size. Journal of Geoscience and Environment Protection, 8, 18-31. https://doi.org/10.4236/gep.2020.84002

[11] Tao, S.l., Li, Y.h. and Mugume, I. (2019) Model Terrain Correction Using Variational Adjoint Method with Tikhonov-Total Variation Regularization. Journal of Physics. Conference Series, 1176, Article ID: 022034. https://doi.org/10.1088/1742-6596/1176/2/022034

[12] Mugume, I., Mesquita, M., Bamutaze, Y., Ntwali, D., Basalirwa, C., Waiswa, D., Reuder, J., Twinomuhangi, R., Tumwine, F., Ngailo, T.J. and Ogwang, B.A. (2018) Improving Quantitative Rainfall Prediction Using Ensemble Analogues in the Tropics: Case Study of Uganda. Atmosphere, 9, 328. https://doi.org/10.3390/atmos9090328

[13] Piani, C., Haerter, J.O. and Coppola, E. (2010) Statistical Bias Correction for Daily Precipitation in Regional Climate Models over Europe. Theoretical and Applied Climatology, 99, 187-192. https://doi.org/10.1007/s00704-009-0134-9

[14] Sharma, A. and Goyal, M.K. (2020) Assessment of the Changes in Precipitation and Temperature in Teesta River Basin in Indian Himalayan Region under Climate Change. Atmospheric Research, 231, Article ID: 104670.

https://doi.org/10.1016/j.atmosres.2019.104670

[15] Ghimire, U., Srinivasan, G. and Agarwal, A. (2019) Assessment of Rainfall Bias Correction Techniques for Improved Hydrological Simulation. International Journal of Climatology, 39, 2386-2399. https://doi.org/10.1002/joc.5959

[16] Cannon, A.J., Sobie, S.R. and Murdock, T.Q. (2015) Bias Correction of GCM Precipitation by Quantile Mapping: How Well Do Methods Preserve Changes in Quantiles and Extremes? Journal of Climate, 28, 6938-6959. https://doi.org/10.1175/JCLI-D-14-00754.1

[17] Monaghan, A.J., Steinhoff, D.F., Bruyere, C.L. and Yates, D. (2014) NCAR CESM Global Bias-Corrected CMIP5 Output to Support WRF/MPAS Research.

[18] Myo, H.T., Zin, W.W., Shwe, K.P., San, Z.M.L.T., Kawasaki, A. and Acierto, R.A. (2020) Projecting the Impact of Climate Change on Temperature, Precipitation, and Discharge in the Bago River Basin. Journal of Disaster Research, 15, 324-334. https://doi.org/10.20965/jdr.2020.p0324

[19] Mahmood, R. and Babel, M.S. (2013) Evaluation of Sdsm Developed by Annual and Monthly Sub-Models for Downscaling Temperature and Precipitation in the Jhelum Basin, Pakistan and India. Theoretical and Applied Climatology, 113, 27-44. 
https://doi.org/10.1007/s00704-012-0765-0

[20] Nalukwago, A., Nanteza, J. and Mugume, I. (2019) Drought Characteristics within Ugandas Cattle Corridor under a Changing Climate. AGU Fall Meeting 2019, AGU, Washington DC.

[21] Smitha, P.S., Narasimhan, B., Sudheer, K.P. and Annamalai, H. (2018) An Improved Bias Correction Method of Daily Rainfall Data Using a Sliding Window Technique for Climate Change Impact Assessment. Journal of Hydrology, 556, 100-118. https://doi.org/10.1016/j.jhydrol.2017.11.010

[22] Tao, S.L., Shen, S.H., Li, Y.H., Wang, Q., Gao, P. and Mugume, I. (2016) Projected Crop Production under Regional Climate Change Using Scenario Data and Modeling: Sensitivity to Chosen Sowing Date and Cultivar. Sustainability, 8, 214. https://doi.org/10.3390/su8030214

[23] Ngailo, T., Shaban, N., Reuder, J., Rutalebwa, E. and Mugume, I. (2016) Non Homogeneous Poisson Process Modelling of Seasonal Extreme Rainfall Events in Tanzania. International Journal of Science and Research, 5, 1858-1868.

[24] Dong, N., Liu, Z., Luo, M., Fang, C.Y. and Lin, H. (2019) The Effects of Anthropogenic Land-Use Changes on Climate in China Driven by Global Socioeconomic and Emission Scenarios. Earth's Future, 7, 784-804. https://doi.org/10.1029/2018EF000932

[25] Nsabagwa, M., Mugume, I., Kasumba, R., Muhumuza, J., Byarugaba, S., Tumwesigye, E. and Otim, J.S. (2018) Condition Monitoring and Reporting Framework for Wireless Sensor Network-Based Automatic Weather Stations. 2018 IST-Africa Week Conference (IST-Africa), Botswana, 9-11 May 2018, 1-8.

[26] Becker, R.A. and Wilks, A.R. (2018) Mapdata: Extra Map Databases. R Package Version 2.3.0.

[27] Fotso-Nguemo, T.C., Chamani, R., Yepdo, Z.D., Sonkoué, D., Matsaguim, C.N., Vondou, D.A. and Tanessong, R.S. (2018) Projected Trends of Extreme Rainfall Events from CMIP5 Models over Central Africa. Atmospheric Science Letters, 19, e803.

[28] Skamarock, W.C., Klemp, J.B., Dudhia, J., Gill, D.O., Barker, D.M., Wang, W. and Powers, J.G. (2008) A Description of the Advanced Research WRF Version 3. NCAR Technical Note-475+ STR.

[29] Mugume, I., Waiswa, D., Mesquita, M.D.S., Reuder, J., Basalirwa, C., Bamutaze, Y., Twinomuhangi, R., Tumwine, F., Sansa-Otim, J., Jacob Ngailo, T. and Ayeslaga, G. (2017) Assessing the Performance of WRF Model in Simulating Rainfall over Western Uganda. Journal of Climatology and Weather Forecasting, 5, 1-9.

[30] Ingula, R.O. and Mugume, I. (2019) Analysis of WRF Simulation Skill for Seasonal Rainfall: A Case Study of 2015 September-November Season. Preprints.

[31] Jeworrek, J., West, G. and Stull, R. (2019) Evaluation of Cumulus and Microphysics Parameterizations in WRF across the Convective Gray Zone. Weather and Forecasting, 34, 1097-1115. https://doi.org/10.1175/WAF-D-18-0178.1

[32] Ngailo, T.J., Shaban, N., Reuder, J., Mesquita, M.D.S., Rutalebwa, E., Mugume, I. and Sangalungembe, C. (2018) Assessing Weather Research and Forecasting (Wrf) Model Parameterization Schemes Skill to Simulate Extreme Rainfall Events over Dar Es Salaam on 21 December 2011. Journal of Geoscience and Environment Protection, 6, 36-54. https://doi.org/10.4236/gep.2018.61003

[33] Das, A.K., Kundu, P.K., Bhowmik, S. and Rathee, M. (2019) Performance Evaluation of WRF Model with Different Cumulus Parameterizations in Forecasting Monsoon Depressions. Mausam, 70, 501-522. 
[34] Hong, S.-Y., Lim, K.-S.S., Lee, Y.-H., Ha, J.-C., Kim, H.-W., Ham, S.-J. and Dudhia, J. (2010) Evaluation of the WRF Double-Moment 6-Class Microphysics Scheme for Precipitating Convection. Advances in Meteorology, 2010, Article ID: 707253. https://doi.org/10.1155/2010/707253

[35] Dudhia, J. (1989) Numerical Study of Convection Observed During the Winter Monsoon Experiment Using a Mesoscale Two-Dimensional Model. Journal of the Atmospheric Sciences, 46, 3077-3107.

https://doi.org/10.1175/1520-0469(1989)046\%3C3077:NSOCOD\%3E2.0.CO;2

[36] Niu, G.-Y., Yang, Z.-L., Mitchell, K.E., Chen, F., Ek, M.B., Barlage, M., Kumar, A., Manning, K., Niyogi, D., Rosero, E., Tewari, M. and Xia, Y.L. (2011) The Community Noah Land Surface Model with Multiparameterization Options (Noah-MP): 1. Model Description and Evaluation with Local-Scale Measurements. Journal of Geophysical Research: Atmospheres, 116. https://doi.org/10.1029/2010JD015139

[37] Mielikainen, M.J., Huang, B., Chen, H., Huang, H.-L.A. and Goldberg, M.D. (2015) Development of Efficient GPU Parallelization of WRF Yonsei University Planetary Boundary Layer Scheme. Geoscientific Model Development, 8, 2977-2990. https://doi.org/10.5194/gmd-8-2977-2015

[38] Varatharajan, R., Manogaran, G., Priyan, M.K., Balas, V.E. and Barna, C. (2018) Visual Analysis of Geospatial Habitat Suitability Model Based on Inverse Distance Weighting with Paired Comparison Analysis. Multimedia Tools and Applications, 77, 17573-17593. https://doi.org/10.1007/s11042-017-4768-9 